\title{
Using Action Research to Organize Technology Transfer in Complex Innovation Contexts
}

\section{Armando Machevo Ussivane and Paul Ellwood}

\author{
(6 Diversity: the art of thinking independently together. \\ Malcolm Forbes (1919-1990) \\ Entrepreneur and publisher
}

\begin{abstract}
Technology transfer projects increasingly consist of multiple, diverse organizations, with each pursuing their own agenda as well as that of the overarching programme. In this article, we adopt a participatory action research methodology in order to explain and improve the coordination of the autonomous innovation activities within an organizationally complex project. The context of the research involved the transfer of rice production technology from China to Mozambique. The action research identified four categories of boundary within the project that were hindering performance: Intellectual/Land property rights; Public/Private sector logics; Inside/Outside programme; and Collaboration/Competition between programme actors. The process of co-inquiry with stakeholders enabled by the action research allowed programme actors to reach an understanding of others, and it created a new thinking space for mutual problem solving. By these means, the action research process makes a resource of the differences between stakeholders rather than it being seen as a barrier to be compromised through negotiation.
\end{abstract}

\section{Introduction}

Technology innovation management increasingly involves working across multiple organizational borders (West \& Bogers, 2017). In addition, the types of organization participating in technology transfer projects are not limited to large, for-profit firms but also involves SMEs (Brunswicker \& Van de Vrande, 2014), universities (Perkmann \& Walsh, 2007), and government agencies (Chesbrough \& DiMinin, 2014). However, a consequence of such organizational complexity is the need for projects to deliver against multiple performance criteria. The resulting models of technology transfer (e.g., Bozeman et al., 2015) can themselves be so complex and contingent that it becomes difficult to discern general implications for the management and organization of such projects. In this article, we adopt an alternative approach to organizing technology transfer in very complex contexts, and we advocate for the use of participatory action research as a means of realizing the diverse objectives of stakeholders while also yielding academic insights.

Action research is designated participatory if it is associated with the emancipation or empowerment of parti- cipants (McTaggart, 1997; Whyte, 1991). The research context of this article is that of agriculture innovation, and this is a context in which participatory forms of action research have become well established (Oreszczyn et al., 2010). They started to be promoted in the 1980s as an alternative over perceived limitations to technology transfer drawn from Rogers' (1962) model of innovation diffusion. At that time, agricultural professionals had begun to realize the inappropriateness of diffusing high-input technologies in diverse, risk-prone and variable farming conditions (Rivera \& Sulaiman, 2009). Participatory research methods became viewed as the types of research needed to empower farmers toward active engagement in knowledge co-creation to solve problems. The underlying assumption was that farmers had considerable relevant and contextual knowledge although their capacity to use and improve such knowledge could be strengthened (Rivera \& Sulaiman, 2009).

Our article reports on a complex context of technology innovation management of significant contemporary importance. The development aid between an economically advanced nation and an emerging nation often includes technology transfer, and it is under-researched in the management literature. Specifically, we 


\section{Using Action Research to Organize Technology Transfer in Complex Innovation Contexts Armando Machevo Ussivane and Paul Ellwood}

examine the case of the transfer of rice production technology between China and Mozambique: the Baixo Limpopo Irrigation Scheme, one of largest technology transfer projects in Africa (Chuanhong et al., 2015). The majority of the research on China-Africa technology transfer has treated China as the dominant driving force in China-Africa relations such that Africans are simply reduced to passive actors (Dollar, 2016). A further limitation of current research is the excessive focus on the nation state with relatively little consideration for micro-level mechanisms of collaboration at the project-implementation level (Chuanhong et al., 2015). The research described in this article operates at the organizational level and documents the application of a participatory action research methodology to enable the coordination of the autonomous activities of the project's different stakeholders. The combination of an action research methodology and a rich data set allows us to explore a range of border issues within a technology transfer project. Rather than framing such borders as something to be broken down, we argue that the very diversity that creates the borders in the first place can be mobilized (through a participatory action research process) to enable project actors to generate insights that lead to the creation of organizational solutions.

\section{Research Issue}

The decision to initiate a technology transfer programme was taken at the level of national economic policy, and it follows decades of economic development collaboration between China and Mozambique. This article is concerned with the organizational level issues of implementing this multi-stakeholder programme. In the early months of the programme, it was evident that multiple identities, interests, and expectations were hindering efforts to co-ordinate the activities of different stakeholders. In this section, we present an account of the programme complexity underpinning this issue by describing the programme context and drawing upon research literature relevant to this context. The objective of the participatory action research project is then understood as providing a more thorough understanding of the programme complexity and developing solutions to coordinate the technology transfer activities of autonomous stakeholders.

\section{Research context}

The context of this research is one of the most significant contemporary Chinese agricultural investments in Africa and involves the transfer of rice farming technologies from China to Mozambique (Chuanhong et al., 2015). These technologies range from high-tech (e.g., new seed varieties) to low-tech (e.g., irrigation and pregermination) and involve the adoption of new (innovative in context) work practices (e.g., soil paddling). The efficacy of new agricultural practices and the viability of new seed varieties in the Mozambique bio-physical environment had previously been tested in demonstrator projects at the level of "friendship farms". The technology transfer programme that we report on in this article was concerned with a step-change scale-up in operations that involved an investment of $\$ 250$ million USD and that employed 2,000 local workers in addition to 700 Chinese workers. The programme was coordinated by a Mozambique Government agency (hereafter RBL) under a platform of cooperation with Wanbao, a private agricultural enterprise from Hubei province (China). The Chairman of RBL is a co-author (AU) of this article and facilitated the participatory action research group.

The complexity of this technology innovation context is evident not only in the variety of technology types but also in the diverse array of autonomous participants (government and local public agencies, local and international farmers, NGOs, banks, and private firms), their different national cultures and different agenda. We suggest that this context is representative of contemporary knowledge transfer where diverse and large numbers of different stakeholders are involved. Seeking to address what we know already about organizing technology transfer in such contexts, we examined the literature related to agricultural technology adoption, cross-cultural relations, and inter-organizational collaborations.

\section{Literature review}

Agricultural innovation scholars (Li et al., 2014; Rogers, 1962; Rogers \& Shoemaker, 1971) have approached technology transfer in terms of the processual relationship between technology source and technology recipient. Consistent with this view, Rogers (1962) advanced a model of the technology transfer as a diffusion of innovation whereby practices or ideas considered new originate in research or science and are then applied to the production process, after which they are diffused (by imitation or through active technology transfer) to the consumers (recipients) if economically successful. Difficulties for effective transfer may happen because much of the expertise is tacit in nature. This tacit dimension reflects the fact that part of knowledge associated with technologies is embedded in processes and behaviours of people (Polanyi, 1966): it is accumulated through practical skills or experiences, and it is therefore difficult to formalize and share with others. The 


\section{Using Action Research to Organize Technology Transfer in Complex Innovation Contexts Armando Machevo Ussivane and Paul Ellwood}

challenge of technology transfer may be heightened because stakeholders have different national cultures.

Culture has been conceptualized as "the collective programming of the mind which distinguishes one group or category of people from another" (Hofstede, 1993), in a way that cultural distance has a strong implication on the nature of transacting patterns between the people involved. Hofstede (1980) has mapped national cultures onto a multi-dimensional framework showing how difference in cultural orientations among people lead to misinterpretations during interaction. People improve their communication with one another by developing their intercultural competence (Lloyd \& Hartel, 2010). This allows them to evaluate more accurately how their own behaviour is affecting cross-cultural collaboration. The negotiation of interpretive differences may be mediated through the activity of translation (Kellogg et al., 2006) and through learning about the differences (Carlile, 2002).

The inter-organizational collaboration literature delineates the forces driving collaboration among autonomous organizational stakeholders. This raises challenges from the fact that each stakeholder must comply with its own agenda, while at the same time committing towards a shared programme purpose. Since neither hierarchy structure of authority nor market exchange enforcements are applicable in such a context (Powell, 1990), the stakeholders are driven into engagement by their high stake and interdependence and the desire to realize mutual gains (Thomson \& Perry, 2006). In order for these to be realized, trust among project stakeholders is needed.

The three threads of literature examined in this section explain the ways in which the management task faced by stakeholders in this context is complex. However, this very complexity prevents a simple application of literature models and frameworks. We argue that a participatory action research methodology is necessary in such circumstances, not only (as discussed above) to empower all stakeholders and unlock their tacit knowledge, but also to mobilize ideas from the literature. In this manner, these literatures did not provide a strong framing of the research, but rather constituted one guide during the discussions in the participatory action research sessions. The literature became, in effect, but one "voice" within the participatory action research process. In summary, an exploratory research question was posed to guide our empirical work: how can the coordination of interdependent activities be achieved in technology transfer programmes consisting of multiple stakeholders? Participatory action research, with its commitment to collaboration between stakeholders in pursuit of both scientific insight and practical impact, is particularly suited to addressing this question.

\section{Methodology}

Participatory action research was adopted in order to give voice to otherwise marginalized perspectives and because it operates by purposefully encouraging people with diverging ideas and mindsets to work together. Adopting participatory action research as a research methodology is to recognize that a collective agency resides within such projects. Notwithstanding the pedigree of the participatory action research methodology within agricultural innovation settings, the decision to adopt the method was taken by AU (co-author and Chairman of RBL) following his own observations of breakdown in the coordination of autonomous programme activities. This very decision by a senior manager risks being problematical in relation to the emancipatory philosophy of participatory action research. Therefore, the research design incorporated a "pre-participatory action research" stage that sought to elicit a wide range of viewpoints on the organizational challenges within the programme, and to test interest in a participatory action research project. Thus, Stage 1 of the research design involved semi-structured interviews with representatives of all programme's stakeholders (17 interviews). These interviews revolved around participants' experience of working with other organizations in the programme and their contribution to the programme's aims. Each participant was approached on the basis that they had been involved in the project for at least one year. The interviews incorporated a conversation about the idea of forming a group of all stakeholders in order to collectively examine the findings from the interviews, and they engaged in a process of identifying, implementing, and evaluating actions to improve the organizational arrangements within the programme (i.e., a participatory action research project). This proposal met with unanimous interest and the second stage of the research design was pursued.

Stage 2 involved convening a participatory action research group constituted of representatives of major stakeholders (Table 1). The participatory action research group discussions were facilitated by AU using the Torbert and Associates action inquiry process (2004). This process seeks to combine inquiry with advocacy by placing in a public forum specific suggestions, inferences, and assumptions in order to subject 


\section{Using Action Research to Organize Technology Transfer in Complex Innovation Contexts Armando Machevo Ussivane and Paul Ellwood}

them to critique and testing. At the first meeting, AU presented his thematic analysis of the Stage 1 interview data. In this manner, the findings of Stage 1 became a resource for the group in their first cycle of action and reflection. Subsequent cycles worked through the production of an action plan to improve the management of the programme, its implementation, and its evaluation. Data were collected during these action-related phases of the research in the form of workshop notes, programme documents, audio-taped observations, AU's research journal, and field notes.

\section{Research Findings}

Stage 1: Constructing the issue

In keeping with the methodological commitment not to impose possible solutions that originated external to the programme, the first stage of the research design sought to engage all stakeholders in the definition of the organizational issue to be addressed. The literature review was useful in guiding the search for data. However, care was taken to ensure the questioning remained openended and did not constrain discussion to categories from the innovation literature. A thematic analysis (Gioia et al., 2013) was conducted with the aim of articulating a grounded theory of the technology innovation management process operating in the programme. This was summarized into three broad phases of initial conditions, stakeholder engagement mechanisms, and desired conditions.

Regarding initial conditions, interviewees agreed that the key programme inputs were Chinese rice-farming technology and practices, along with the bio-physical factors of the programme's location. As the new technology was mobilized in this setting the initial challenges included the set-up and technology demonstration. The change in bio-physical context from that of China and the earlier "friendship farms" necessitated both the modification of agricultural practices and the creation of new policy instruments (e.g., in relation to land allocation).

The operation of the programme involved partners interacting with each other in multiple ways. The interviews afforded a rich picture of innovation activities as stakeholders pursued their own agendas in collaboration with programme partners. Three sub-themes of mechanism emerged from the analysis: the varied motivations for joining the programme; partnership forums and meetings; and integrating the work of different groups in order to adapt the technology to

Table 1. List of participatory action research participants

Organization Role in the Programme

RBL (government agency responsible for coordinating programme)

Farmers
Position of the Participant

- Chief Executive (and co-author AU)

- 5 local farmers

- President of Farming Association

- Young graduate farmer

Chinese Investment Company

- Local manager

- Technical staff

Mozambique Government Agencies

- District commissioner

- District director of economic activities

Local NGO - Women Development Fund (FDM)

- Local manager

Private financial services provider

- Local manager

Local government agency responsible over media broadcasting

- Local coordinator

Local NGO for community mobilization and advocacy over land-related issues

Local private agricultural firm providing land preparation services 


\section{Using Action Research to Organize Technology Transfer in Complex Innovation Contexts Armando Machevo Ussivane and Paul Ellwood}

local conditions. In addition to detailing these engagement mechanisms, interviewees spoke of the problems that had emerged. For example, one of the research participants we interviewed said about his work relationship with the Chinese partners, "My work with the Chinese has become transaction-based and is not cooperation anymore... I have to pay money to receive full package of services from the Chinese." His words exemplify how most farmers in the programme viewed their engagement with the Chinese in the programme. However, they also show a lack of alignment with the programme obligations of the Mozambique/China partnership agreement reached at a political level. Finally, in speaking about their hopes for the project, the interviewees made evident the different organizational agendas that were running in parallel, and that needed integration. The interviews validated the objective of the research: to improve the coordination (integration of interdependent activities) between the programme's stakeholders. The experiences captured through the interviews, and their processual ordering following thematic analysis, provided a rich picture of how technology transfer was being organized within the programme. It constituted a comprehensive resource with which to initiate the participatory action research stage of the research design.

\section{Stage 2: Participatory action research sessions}

The rich processual picture generated from the interviews was used to stimulate discussion in the participatory action research group sessions. Using this forum empowered participants toward active engagement in the creation of an agenda for social change. Experiences and stories from the programme were shared and examined for common themes. The tensions and conflicts within the programme could be understood in relation to "boundaries", which highlighted differences in meanings, behaviours, attitudes, or values. These boundaries are presented in Table 2 and are explained in the following sub-sections.

\section{Property rights boundary (intellectual vs land)}

A conflict emerged concerning land use within the geographical area of the programme. This was manifest as demands from the local community that they be granted access to the programme's developed land as a form of compensation after their grazing land had suffered reduction as a consequence of the programme. Under Mozambican land law, the State retains ownership of all land (and so could allocate land for the programme) and yet the rights and participation of local communities in land tenure (customary land use rights by fact of occupation) are stronger. Granting such access meant

Table 2. Summary of tensions at different boundaries within the technology transfer programme

Boundary Nature of Organizational Tension

Intellectual - Land

(property rights)

Return on investment for the provision of intellectual property

- versus -

Return from exercise of traditional land rights

Public - Private

Long-term aim of public policy to improve performance of rice farming through the introduction of new technologies and practices,

- versus -

Short-term aim of private firms to survive by optimizing business operations

Inside - Outside

(programme)

Obligation to work only with and through those partners identified with the programme

- versus -

Freedom to work with any organization offering suitable services or products

Collaboration -

Competition

Chinese actors as collaborators supporting Mozambicans through active development aid

- versus -

Chinese actors as competitors to Mozambican farmers and businesses 


\section{Using Action Research to Organize Technology Transfer in Complex Innovation Contexts Armando Machevo Ussivane and Paul Ellwood}

the local people being trained in the new rice-growing practices. However, there was a high likelihood of production losses during the training period, which represented a risk to private investors in the new technology.

This new understanding - a shift from a comparison of loss and subsequent compensation into an understanding of the challenge as one of de-risking losses for both investors and community - translated into social change. There was a change in attitude from stakeholders as evidenced by an agreement between RBL and a Chinese private investor to co-finance costs for training of local farmers. In addition, an assurance was given that large farming plots in developed areas were gradually allocated to local farmers after they were rigorously selected and had successfully completed training in a small size of plot.

\section{Tensions between public policy and private business}

Stakeholders diverged in their views regarding the ongoing policy agenda, which encourages optimization of land use through growing of rice twice a year. It had become costly researching adaptable new varieties of rice seeds to achieve this goal, within a programme that was experiencing operational difficulties and struggled to survive. Discussions in the participatory action research sessions revolved around whether the programme, rather than pursue agricultural research goals with a long-term reward horizon, should rather limit its focus to more short concerns of the farmers (e.g., improving the management of irrigation infrastructure). As a Chinese investor explained: “...the project cannot survive and help farmers if it does not make money... there is need to divide the risks between partners and to do profitable operations now...". By realizing the need for change in the research agenda, the Chinese investor and RBL were able to establish a research unit that helped to address the immediate and practical problems in the programme.

\section{Tensions between participants inside the programme and agricultural firms outside it}

Local farmers argued for the right to use alternative service providers (to the Chinese) and to purchase cheaper fertilizer in local markets. In this way, they were wanting to make use of their own local knowledge. And yet, the overarching (China-Mozambique) partnership agreement that helped to secure land, financing, and government support also implied obligations between farmers and Chinese technology providers. A local farmer in the meeting talked about the need to improve the selling of rice production: “...the project needs to change from the current scheme in which we sell all our rice to the Chinese." A second local farmer explained in the following terms, "Part of our technology can be used within the Chinese technology, ...the fertilizers we use in the programme should be the ones we are already used to. This would reduce our dependence." The tensions between national and local interests were also evident here, with the farmers wanting to break the rules of the business model to optimize their income. The path creative (and emergent) nature of the technology innovation were evident through this research as local farmers and Chinese modified and adapted some of their existing knowledge to suit the context of the programme.

\section{Tensions between partner in aid and private investor (collaborator or competitor)}

From the earliest days of Mozambique's independence from Portuguese colonial rule, China had been viewed as a strategic partner for economic development. The programme itself was a product of three decades of China-Mozambique collaboration, and yet the very complexity of the programme created role conflict. In one of the participatory action research sessions, a technician from the Chinese investment company explained that, following the construction of the irrigation system, they had allocated developed farms to four Chinese State farms that also were provided with the responsibility to provide farming services and technical assistance to local farmers. These Chinese teams owned and had full control of most of the machinery and equipment for rice farming. The investment company retained responsibility for buying the farmers' rice production and the control of the rice processing facilities. Reacting to this information, a manager from a local farm holding company said of the Chinese business model, "These Chinese teams are also farmers doing business... they could never transfer the technology successfully to the local farmers". The social actions and empowerment following these participatory action research discussions were realized as the Chinese investor, Chinese teams, and RBL were recommended by the participatory action research group to undertake segregation of their roles: the role of knowledge transfer was separated from that of service provider and farmers' buyer.

\section{Discussion}

Through this research, we sought to answer the question: how can the coordination of interdependent activities be achieved in technology transfer programmes consisting of multiple stakeholders? The discussion considers the way in which the participatory action research process contributed to and influenced the 


\section{Using Action Research to Organize Technology Transfer in Complex Innovation Contexts Armando Machevo Ussivane and Paul Ellwood}

performance in this technology transfer programme. We argue that adopting this methodology allowed participants not only to identify different categories of border and their associated tensions, but also to use this knowledge to initiate new organizational solutions. The mechanisms behind this research process are not concerned with dissolving boundaries between groups, but rather enabling ways of working across those boundaries. This research is therefore germane to the idea explored in this special issue concerning the benefits of action research for breaking down borders, broadening participation, and increase the relevance of innovation management research. We suggest that combining participatory action research with the boundary and translation focus represents a methodological contribution in inquiring into technology transfer/translation and in dealing with it to reach practical effects in diverse, changing, and complex organizational settings. Unlike conventional social science research, whose desire is to describe, understand, and explain the world (Coghlan, 2011), participatory action research changes the world. We suggest that methodologies without action inquiry at their core would not have worked since they do not change people's views, nor empower them. In this section, we discuss how participatory action research contributed to achieving research findings and enabled subsequent impacts by reflecting upon the following four themes: diversity of participants, need to deliver practical benefits and people empowerment, path creative nature of contemporary technology innovation, and complexity in the programme.

The wide diversity of stakeholders was made manifest through the participatory action research process through the different types of contribution that participants brought to the participatory action research sessions. The Chinese investors and farmers contributed their experience in technology diffusion and cross-cultural interaction in the programme; the agricultural service firm and financing service provider shared their expertise in organizing supply chains. Helping to surface and translate (Kellogg et al., 2006) the community perspectives was one role played by a few organizations, namely the local non-governmental organization for land rights, a local government broadcasting agency, Mozambique government agencies, and a local women development fund. Every stakeholder in the programme was autonomous, pursuing its own mission, while also committing towards a shared programme purpose. The participatory action research methodology brought an inquiry orientation to the participants. Despite the appearance of large differences in knowledge, financial capacity, and political resources, the participatory action research process still allowed participants to work together.

The practical benefits of participatory action research are manifest in the way in which participant discussions were being translated into social actions and people empowerment. Adopting a forum and set of reflection routines that gives voice to all participants' experience makes possible the creation of an agenda for social change and people empowerment. Participation in such an (action research) forum motivates participants to seek new explanations in light of current dissatisfactions. And, introducing different perspectives as an aid to inquiry (rather than a negotiation position) enables problem solving and leads to the formation of collective judgements. The participatory action research process helped participants to clarify the issues and challenges facing them, created awareness of the need for action, focused attention on specific areas of concern, identified resources and strategies for change, and helped to assess the impact of those strategies. By means of increasing participants' control over their own situations, an emancipatory outcome was realized: local communities (via farmers' contributions to the participatory action research forums) were not simply the recipients of aid but were able to contribute to the way in which the programme was enacted.

That social actions and empowerment were realized is illustrated in the way in which the conflict between land and intellectual property rights was resolved through the participatory action research process. The case for expecting returns on these different categories of property rights was judged reasonable once the owners of those rights had a forum to explain their dissatisfactions. This led to the challenge at hand being re-framed as a matter of de-risking both losses, rather than comparison of loss and subsequent compensation. This, in turn, enabled the identification and testing of de-risking actions. The end result saw the RBL and Chinese private investor reach agreement in two areas: i) co-financing costs for training of local farmers and ii) assuring that large farming plots in developed areas were gradually allocated to local farmers after they were rigorously selected and had successfully completed training in a small size of plot.

Following a participatory action research methodology is consistent with the path creative nature of contemporary technology innovation. Garud, Kumaraswamy, and Karnøe (2010) argue that the path creative nature of such innovation is founded upon a notion of agency 


\section{Using Action Research to Organize Technology Transfer in Complex Innovation Contexts Armando Machevo Ussivane and Paul Ellwood}

that is distributed and emergent through relational processes between diverse stakeholders. Contemporary technology innovation is characterized as working across boundaries (e.g., West \& Bogers, 2017), and it is subject not only to the absence of a common syntax and interpretive differences that result from stakeholders' different national cultures, but also to dependences between actors (Carlile, 2004). Actors' dependences in this programme were made evident through the discussions and experimentation within the participatory action research methodology as local farmers and Chinese actors modified and adapted some of their existing knowledge to the new context.

As the study's findings illustrate, action research succeeds when working across borders, because it surfaces differences and makes a resource of them, rather than hardening the differences into a barrier to be knocked down. Consistent with Bartel and Garud's (2009) theory of innovation narratives, this sharing and exploring of experiences shows that knowledge does not simply diffuse (cf. Rogers, 2003), but rather there is an active process of continuous translation wherein current knowledge (localized, embedded, and invested in practice) is transformed through application to a given context. This process was judged effective to the extent that the participatory action research sessions were continued within the technology transfer programme after the formal research study had finished.

The complexity of the whole programme evident throughout this discussion means that the adoption of a systemic methodology like participatory action research is preferred if the research objective is more than simply introducing a new technology. There was not only technology change in the programme but also: changes in user practices and institutional structures; the introduction of complementary technology; the design of new supply chains; and the construction of modern agricultural infrastructures. Challenges in such a system emerge as a result of multiple causes and effects that interact over time (Coghlan \& Brannick, 2010). The participatory action research methodology provided a perspective on understanding how the programme was held together by patterns of action and reaction, relationships between actors, different meanings they constructed and their hidden assumptions, and how all these changed over time. In realizing research impacts, then, participatory action research also considered interventions that enabled changes in these patterns, where required.

\section{Conclusion}

The starting premise for this article was that the increasing stakeholder diversity within contemporary technology transfer projects necessitated new approaches to both researching those projects, as well as realizing diverse practical impacts. We adopted a participatory action research methodology within an organizationally complex technology transfer project in order to explain and improve the coordination of the autonomous activities of the project's varied stakeholders. The action research surfaced four categories of organizational boundary within the project that were hindering performance. These boundaries between groups could be explained in terms of differences in the institutional logics and tacit knowledge that constitute the agendas of different stakeholders. That these agendas were highly invested in the practices of stakeholders explains the observed difficulties in coordinating dependent innovation activities. The process of co-inquiry with stakeholders that action research enabled allowed programme actors to reach an understanding of others, and it created a new thinking space for mutual problem solving. By these means, the action research process mobilized the differences between stakeholders as a resource for problem solving, rather than it being seen as a barrier to be compromised through negotiation.

Finally, the positioning (cf. Herr \& Anderson, 2005) of co-author AU as contributing both outside the project (as a scholar) and inside (as a practitioner) merits further research in other technology management contexts. In this study of exploring boundaries, then having a facilitator who themselves operated at the border between the scholarly (being an expert with the theoretical background to the study and methodology) and the practitioner (being knowledgeable about the technology domain) brought another beneficial source of diversity for realizing the research objectives. 


\section{Using Action Research to Organize Technology Transfer in Complex Innovation \\ Contexts Armando Machevo Ussivane and Paul Ellwood}

\section{About the Authors}

Armando Machevo Ussivane is the Chairman of RBL, E.P - a Mozambique Government agency in charge of the management of the Baixo Limpopo Irrigation Scheme. The objectives of this scheme are food security and poverty alleviation through improved agricultural productivity. His career includes 18 years of experience in the management of agriculture development projects. His research interests lie within the areas of inter-organizational collaboration including partnerships and technology transfer in cross-cultural agriculture contexts. Armando holds a Doctorate in Business Administration from the University of Liverpool, United Kingdom.

Paul Ellwood is a Senior Lecturer in Management at the University of Liverpool. His research interests are broadly in the area of science-led innovation and include technology transfer, responsible innovation, and the organization of university scientific research groups. His early career included leadership positions in a private science-based industry. Since moving to a university management school, he has become increasingly interested in issues relating to the engagement between academic research and management practice.

\section{References}

Bartel, C. A., \& Garud, R. 2009. The Role of Narratives in Sustaining Organizational Innovation. Organization Science, 20(1): 107-117. https://doi.org/10.1287/orsc.1080.0372

Bozeman, B., Rimes, H., \& Youtie, J. 2015. The Evolving State-of-theArt in Technology Transfer Research: Revisiting the Contingent Effectiveness Model. Research Policy, 44(1): 34-49. https://doi.org/10.1016/j.respol.2014.06.008

Brunswicker, S., \& van de Vrande, V. 2014. Exploring Open Innovation in Small and Medium-Sized Enterprises. In $\mathrm{H}$. Chesbrough, W. Vanhaverbeke, \& J. West (Eds.), New Frontiers in Open Innovation: 135-156. Oxford: Oxford University Press.

Carlile, P. R. 2004. Transferring, Translating, and Transforming: An Integrative Framework for Managing Knowledge Across Boundaries. Organization Science, 15(5): 555-568. https://doi.org/10.1287/orsc.1040.0094

Carlile, P. P. 2002. A Pragmatic View of Knowledge and Boundaries: Boundary Objects in New Product Development. Organization Science, 13(4): 442-455.

https://www.jstor.org/stable/3085976
Chesbrough, H., \& DiMinin, A. 2014. Open Social Innovation. In H. Chesbrough, W. Vanhaverbeke, \& J. West (Eds.), New Frontiers in Open Innovation: 169-188. Oxford: Oxford University Press.

Chuanhong, Z., Xiaoyun, L., Gubo, Q., \& Yanlei, W. 2015. Interpreting China-Africa Agricultural Encounters: Rhetoric and Reality in a Large Scale Rice Project in Mozambique. Future Agricultures, Working Paper, 126: 1-17.

Coghlan, D. 2011. Action Research: Exploring Perspectives on a Philosophy of Practical Knowing. The Academy of Management Annals, 5(1): 53-87.

https://doi.org/10.1080/19416520.2011.571520

Coghlan, D., \& Brannick, T. 2010. Doing Action Research in Your Own Organisation (3rd ed.) London: SAGE.

Dollar, D. 2016. China's Engagement with Africa - From Natural Resources to Human Resources. John L. Tornton China Center Working Paper. Washington, DC: Brookings Institution.

Garud, R., Kumaraswamy A., \& Karnøe, P. 2010. Path Dependence or Path Creation? Journal of Management Studies, 47(4): 760-774. https://doi.org/10.1111/j.1467-6486.2009.00914.x

Gioia, D. A., Corley, K. G., \& Hamilton, A. L. 2013. Seeking Qualitative Rigor in Inductive Research: Notes on the Gioia Methodology. Organizational Research Methods, 16(1): 15-31. https://doi.org/10.1177/1094428112452151

Herr, K., \& Anderson, G. L. 2005. The Action Research Dissertation: A Guide for Students and Faculty. Thousand Oaks, CA: SAGE Publications Inc.

Hofstede, G. 1993. Cultural Constraints on Management Theories. Executive, 7(1): 81-94. https://www.jstor.org/stable/4165110

Hofstede, G. 1980. Culture's Consequences: International Differences in Work-Related Values. Beverly Hills, CA: SAGE.

Kellogg, K. C., Orlikowski, W. J., \& Yates, J. 2006. Life in the Trading Zone: Structuring Coordination Across Boundaries in Postbureaucratic Organizations. Organization Science, 17(1): 22-44.

https://doi.org/10.1287/orsc.1050.0157

Li, J. H., Chang, X. R., Lin, L., \& Ma, L. Y. 2014. Meta-Analytic Comparison Influencing Factors of Knowledge Transfer in Different Cultural Contexts. Journal of Knowledge Management, 18(2): 278-306.

https://doi.org/10.1108/JKM-08-2013-0316

Lloyd, S., \& Hartel, C. 2010. Intercultural Competencies for Culturally Diverse Work Teams. Journal of Managerial Psychology, 25(8): 845-875.

https://doi.org/10.1108/02683941011089125

McTaggart, R. 1997. Guiding Principles for Participatory Action Research. In R. McTaggart (Ed.), Participatory Action Research: 25-43. Albany, NY: University of New York Press.

Oreszczyn, S., Lane, A., \& Carr, S. 2010. The Role of Networks of Practice and Webs of Influencers on Farmers' Engagement with and Learning about Agricultural Innovations. Journal of Rural Studies, 26(4): 404-417.

https://doi.org/10.1016/j.jrurstud.2010.03.003

Perkmann, M., \& Walsh, K. 2007. University-Industry Relationships and Open Innovation: Towards a Research Agenda. International Journal of Management Reviews, 9(4): 259-280. https://doi.org/10.1111/j.1468-2370.2007.00225.x 


\section{Using Action Research to Organize Technology Transfer in Complex Innovation \\ Contexts Armando Machevo Ussivane and Paul Ellwood}

Polanyi, M. 1966. The Tacit Dimension. New York: Anchor Day Books.

Powell, W. W. 1990. Neither Market nor Hierarchy: Network Forms of Organisation. Research in Organisational Behaviour, 12: 295-336.

Rivera, W. M., \& Sulaiman, V. R. 2009. Extension: Object of Reform, Engine for Innovation. Outlook on Agriculture, 38(3): 267-273. https://doi.org/10.5367/000000009789396810

Rogers, E. M. 2003. Diffusion of Innovation (5th ed). New York: Free Press.

Rogers, E. M. 1962. Diffusion of Innovations. New York: The Free Press of Glencoe.

Rogers, E. M., \& Shoemaker, F. F. 1971. Communication of Innovations: A Cross Cultural Approach. New York: Free Press.

Thomson, A. M., \& Perry, J. L. 2006. Collaboration Processes: Inside the Black Box. Public Administration Review, 66(1): 20-32. https://doi.org/10.1111/j.1540-6210.2006.00663.x

Torbert, W. R. and Associates 2004. Action Inquiry. San Francisco, CA: Berret-Koehler Publishers.

West, J., \& Bogers, M. 2017. Open Innovation: Current Status and Research Opportunities. Innovation: Organization \& Management, 19(1): 43-50. https://doi.org/10.1080/14479338.2016.1258995

Whyte, W. F. 1991. Conclusions. In W. F. Whyte (Ed.), Participatory Action Research: 237-241. Thousand Oaks, CA: SAGE Publications.
Citation: Ussivane, A. M., \& Ellwood, P. 2019. Using Action Research to Organize Technology Transfer in Complex Innovation Contexts. Technology Innovation Management Review, 9(4): 17-26.

http://doi.org/10.22215/timreview/ 1230

Keywords: action research, technology transfer, boundaries, international collaboration, agricultural innovation 


\section{TIm Technology Innovation Management Review}

\section{Academic Affiliations and Funding Acknowledgements}
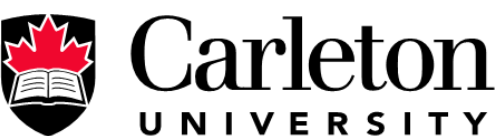

U N I V E R S I T Y

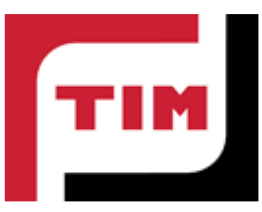

Technology Innovation Management (TIM; timprogram.ca) is an international master's level program at Carleton University in Ottawa, Canada. It leads to a Master of Applied Science (M.A.Sc.) degree, a Master of Engineering (M.Eng.) degree, or a Master of Entrepreneurship (M.Ent.) degree. The objective of this program is to train aspiring entrepreneurs on creating wealth at the early stages of company or opportunity lifecycles.

- The TIM Review is published in association with and receives partial funding from the TIM program. 